\title{
EXPERIMENTAL STUDY ON MECHANICAL PROPERTIES OF POLYURETHANE POWDER COMPOSITES
}

\author{
Kexin Zhang1, 2, Dachao Li², Xinyuan Shen², Xingwei Xue², Dandan $G u^{3}$
}

1. MOE Key Lab of Disaster Forecast and Control in Engineering, Jinan University, No.601 Huangpu Dadao West, Guangzhou, Guangdong Province, PR of China; jt_zkx@sjzu.edu.cn; zkx0204@yahoo.com

2. Shenyang Jianzhu University, School of Traffic Engineering, Department of Bridge, Shenyang, No. 25 Hunnan Middle Road, PR of China;

3. Shenyang Institute of Technology, School of Energy and Hydraulic Engineering, East Section of Binhe Road, Shenfu New District, Liaoning Province, PR of China

\begin{abstract}
In recent years, there have been cases of strengthening bridge structures with polyurethane cement mortar. To further explore the properties of polyurethane materials, the effects of emery, lime, quartz sand and cement on the mechanical properties of polyurethane powder composites are studied by three-point flexural test. In the flexural test, the polyurethane cement composite formed a control group by changing the content of polyester polyol. The flexural strength and ductility are improved to a certain extent due to the addition of polyester polyol. The average flexural strength of other polyurethane powder composites such as polyurethane emery test block is $45.1 \mathrm{MPa}$ and the corresponding strain is $6203 \mu \varepsilon$, the average flexural strength of polyurethane lime test block is 33.4 $\mathrm{MPa}$ and the corresponding strain is $6470 \mu \varepsilon$, the average flexural strength of polyurethane quartz sand test block is $49.23 \mathrm{MPa}$ and the corresponding strain is $7521 \mu \varepsilon$. The results show that the flexural strength of polyurethane emery material and polyurethane quartz sand material is higher than that of polyurethane cement, which can be used to replace cement to a certain extent to reduce the cost of polyurethane composite material.
\end{abstract}

\section{KEYWORDS}

Polyurethane cement (PUC) material, Mechanics performance tests, Polyurethane powder composites, Constitutive relation

\section{INTRODUCTION}

Bridges are important parts of roads and railways, which play indispensable roles in logistics and transportation [1-3]. However, with the development of society, traffic has become increasingly busy. Under certain conditions, such as vehicle load, acid rain, and the rapid increase of temperature, a series of defects of stress cracks, concrete deterioration, and steel corrosion have occurred in the bridge structure [4-6]. After decades of operation, the Bridges built in the early stage are generally aged, and most of them are in the working state of "defcet". Although after years of reinforcement and transformation, the number of dangerous Bridges is still very large. The practice shows that the bearing capacity of the old bridge structure can be restored and improved by using appropriate reinforcement methods. Countries all over the world try to improve the service life of the old bridge by means of reinforcement, so that its bearing capacity can be effectively guaranteed. 


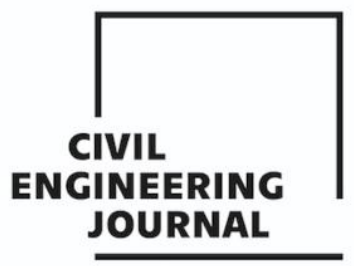

Article no. 67

THE CIVIL ENGINEERING JOURNAL 4-2021

Therefore, how to strengthen the bridge economically, quickly, and effectively becomes one of the key points in the development of bridge industry [7-10].

Polyurethane cement composite (PUC) has the characteristics of light weight, high strength and high toughness, and the material itself has good bonding strength and acid and alkali corrosion resistance, which can not only solve the durability problems of reinforced beams caused by composite mortar cracking and falling off, but also the material itself can be reinforced for the main beam. The traffic management department has used the reinforcement method of polyurethane cement composite material in some actual old bridge reinforcement in recent years. Some domestic scientific research institutions not only study the mechanical properties of polyurethane cement, but also use it comprehensively with the reinforcement method of prestressed steel wire rope, as the embedded material to participate in the stress of the structure, so that the active and passive reinforcement methods cooperate, and become the additional passive reinforcement material for the prestressed reinforcement [11-13]. Scholars have carried out a series of studies on its excellent properties in building materials:

Sun Quansheng et al. [14] tested the tensile and flexural resistance of polyurethane cement through laboratory tests. Zhang Shengran et al. [15] used steel wire rope and polyurethane cement composite steel wire rope to strengthen the bending of $3 \mathrm{~m}$ ordinary reinforced concrete $\mathrm{T}$ beam and made a total of 5 test beams without reinforcement, with 5 separate steel wire rope reinforcement and 3, 5 and 7 steel wire ropes reinforcement of polyurethane cement. They analyzed and verified the reinforcement effect of polyurethane cement steel wire rope on rigidity, strength and bearing capacity. Liu Guiwei, Wang Jianlin et al. [16] through the preparation of materials received pu concrete composite material (MPC), Ningbo-Taizhou-Wenzhou highway of Zhejiang Ningbo Bai Xi bridge has carried on the polyurethane composite reinforcement concrete. Zhang Hongxiang et al. [17] and Gao Feng [18] completed the experimental study of taking MPC composite materials to strengthen $13 \mathrm{~m}$ hollow slab girders. During the whole test, the MPC material and the concrete section did not slip. They established the calculation formula of strain and bending capacity of hollow slab beams after MPC reinforcement, and also verified the feasibility of ANSYS software in the study of simulating MPC reinforcement of RC beams. Gu Dandan et al. [19,20] found that the material can improve the bearing capacity of hollow slab bridges. Haleem K. Hussain et al. [21-23] tried to get polyurethane cement (PUC) composites with polyurethane and fly ash. They carried out flexural and flexural tests on the composites and obtained the stress-strain curves of the materials at different densities. Based on the material research, the bending reinforcement tests of seven T-section beams under different failure degrees are carried out. The results show that the ultimate bearing capacity of the beams strengthened by polyurethane cement composite (PUC) is improved.

However, the cost of the cement in the polyurethane cement is high. If other cheaper materials are used as filling materials, it is a feasible way to greatly reduce the cost of the polyurethane cement material. In this paper, the same weight of quartz sand, lime, emery and other materials will be added to the polyurethane material, through flexural test to explore its mechanical properties.

\section{POLYURETHANE RAW MATERIALS AND PREPARATION Polyurethane Cement Composite (PUC)}

The main chemical composition is shown in Table 1. Polyols usually account for $49 \%$ and isocyanates account for $51 \%$. Polyurethane has excellent performance in mechanical property of good wear resistance, molding properties and chemical corrosion resistance. 
CIVIL

Tab. 1 - Polyurethane ratio

\begin{tabular}{|c|c|c|}
\hline \multicolumn{2}{|c|}{ Composition } & Percentage (\%) \\
\hline \multirow{2}{*}{$\begin{array}{c}\text { Polyols raw } \\
\text { material }\end{array}$} & Polyether & 49 \\
\cline { 2 - 3 } & Silicone Oil & 1 \\
\cline { 2 - 3 } $\begin{array}{c}\text { Isocyanate raw } \\
\text { material }\end{array}$ & Water & $0-1$ \\
\hline
\end{tabular}

\section{Preparation of Polyurethane Powder}

Polyurethane raw materials and silicon carbide, limestone, quartz sand and cement powder according to the quality than the mixture of polymerization reaction, the quality ratio of polyester polyols: isocyanate: powder $=1: 1: 2$, by comparing polyurethane concrete stress and strain characteristics, set up the control group, formulate the polyester polyols: isocyanate: powder $=1.15: 1$ and polyester polyols: Isocyanate: powder = 1.3:1:2 high density polyurethane powder composite material, and for the convenience of explanation. Three groups of polyurethane cement test blocks are named as group A, group B, and group $C$ shown in Table 2. The preparation process is shown in Figure 1 and Figure 2. The size of the test mold is based on the Chinese cement mortar strength inspection method GB/T 17671-2020. The polyurethane powder composite material and defoaming agent are mixed mechanically for $3-5$ mins, then molded into a $40 \mathrm{~mm} \times 40 \mathrm{~mm} \times 160 \mathrm{~mm}$ cuboid specimen and $70 \mathrm{~mm} \times 70 \mathrm{~mm} \times 70 \mathrm{~mm}$ cube specimen. The test blocks after molding are shown from Figure 3 to Figure 6.

Tab. 2 - Specific composition table of polyurethane material sample block

\begin{tabular}{|c|c|c|}
\hline $\begin{array}{c}\text { Types of Polyurethane } \\
\text { Powder }\end{array}$ & Composition & Percentage (\%) \\
\hline \multirow{3}{*}{$\begin{array}{c}\text { Group A Polyurethane } \\
\text { Cement }\end{array}$} & Polyether Polyols & 25 \\
\hline & Isocyanate & 25 \\
\hline & Cement & 50 \\
\hline \multirow{3}{*}{$\begin{array}{c}\text { Group B Polyurethane } \\
\text { Cement }\end{array}$} & Polyether Polyols & 28 \\
\hline & Isocyanate & 24 \\
\hline & Cement & 48 \\
\hline \multirow{3}{*}{$\begin{array}{c}\text { Group C Polyurethane } \\
\text { Cement }\end{array}$} & Polyether Polyols & 30 \\
\hline & Isocyanate & 23 \\
\hline & Cement & 47 \\
\hline \multirow{3}{*}{ Polyurethane Emery } & Polyether Polyols & 25 \\
\hline & Isocyanate & 25 \\
\hline & Silicon Carbide & 50 \\
\hline \multirow{3}{*}{ Polyurethane Lime } & Polyether Polyols & 25 \\
\hline & Isocyanate & 25 \\
\hline & Calcium Carbonate & 50 \\
\hline \multirow{3}{*}{ Polyurethane Quartz Sand } & Polyether Polyols & 25 \\
\hline & Isocyanate & 25 \\
\hline & Quartz Sand & 50 \\
\hline
\end{tabular}




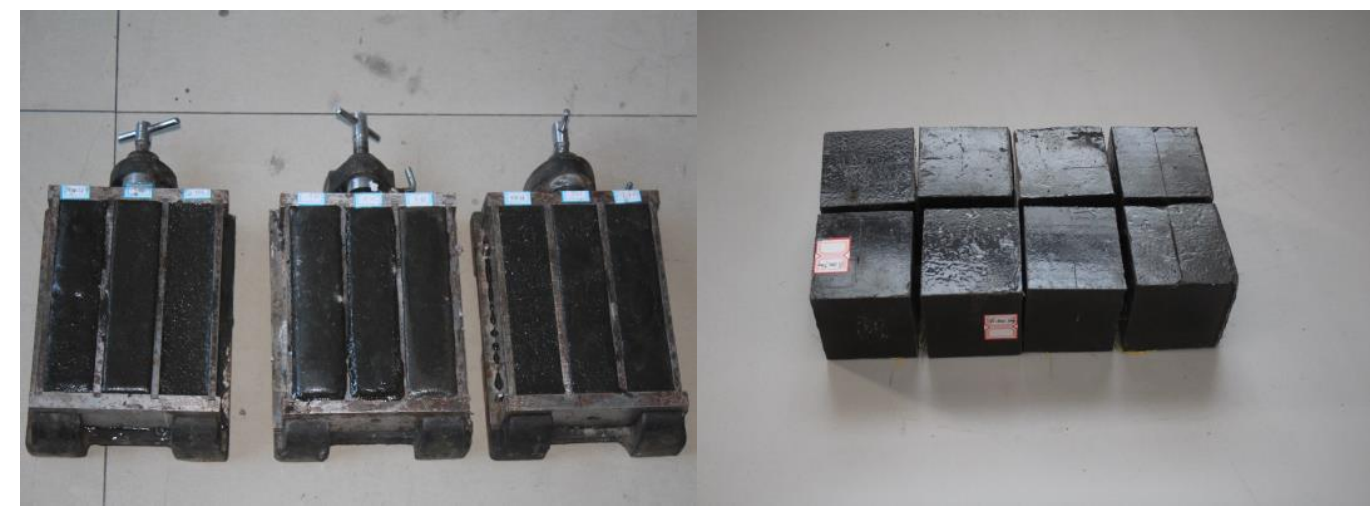

Fig. 1 - Pouring diagram of polyurethane material

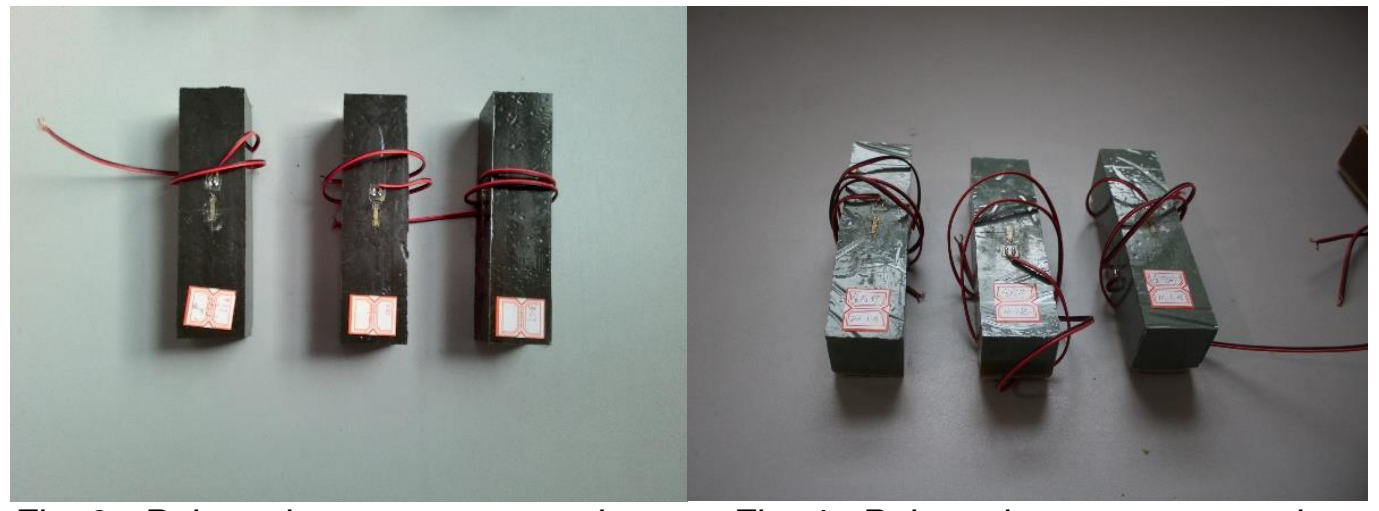

Fig. 3 - Polyurethane cement specimen

Fig. 4 - Polyurethane emery specimen

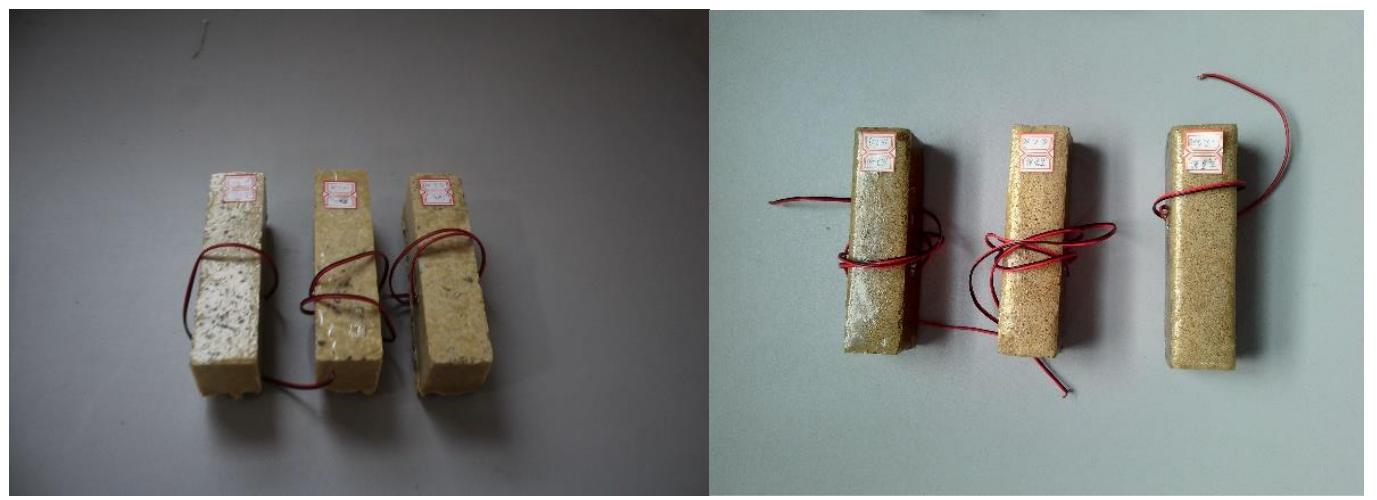

Fig. 5 - Polyurethane quartz specimen

Fig. 6 - Polyurethane lime specimen

\section{LOADING AND MEASURING SCHEME}

Because polyurethane composite material is a new type of material, there is no current specification for its use. Therefore, JTG E30-2005 Test Rules for Cement and Cement Concrete in Highway Engineering is adopted for experimental study. Referring to the test method for the flexural strength of cement concrete cube in the code, the three-point flexural strength test is carried out on the universal tester. According to the rules, the test process should first be the center of the test piece and the press geometric alignment, and then determine the test loading speed. When the test is ready, start loading. When the polyurethane material test block is close to failure and begins to deform rapidly, the test machine is no longer adjusted; When the failure of the polyurethane material test block is determined, the failure ultimate load $\mathrm{F}$ is recorded. After the completion of the test, the 
test data are statistically processed. The flexural strength of polyurethane cement specimens should be calculated as follows:

$$
\sigma_{c}=\frac{1.5 F l}{b h^{2}}
$$

In the formula:

$\sigma_{c} \quad$ The flexural strength of polyurethane cement, Mpa;

$\mathrm{F} \quad$ The ultimate load, $\mathrm{N}$;

$\mathrm{L} \quad$ Distance between support points, $\mathrm{mm}$;

b The width of the prism, $\mathrm{mm}$;

$\mathrm{h} \quad$ The height of the prism, $\mathrm{mm}$;

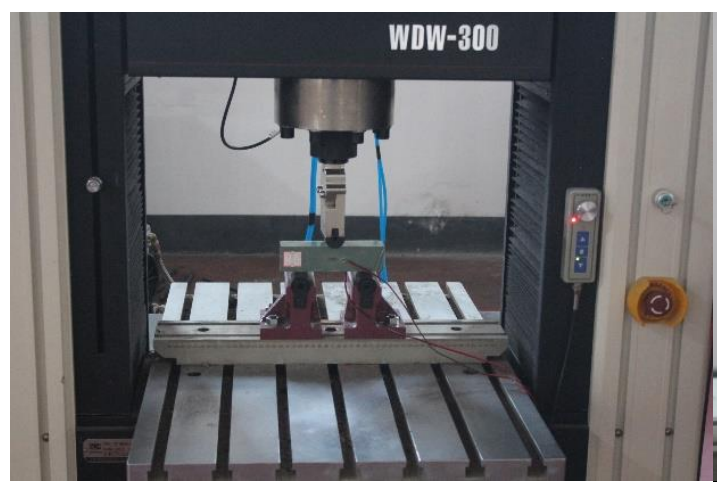

(a)

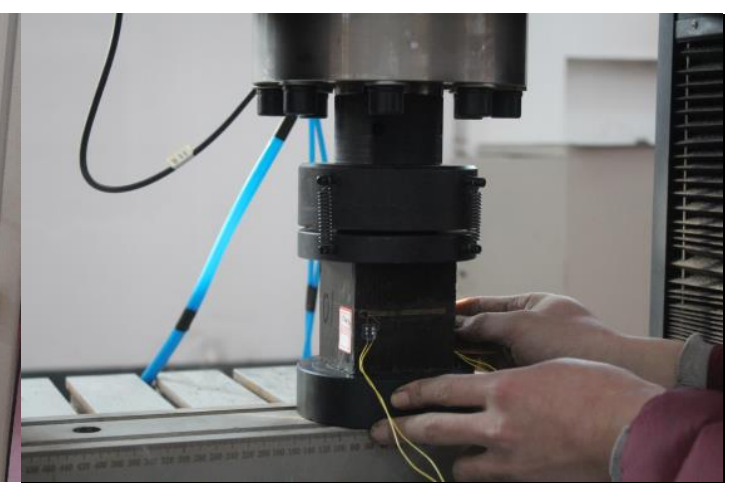

(b)

Fig. 7 - Loading device diagram

\section{EFFECT OF DIFFERENT POWDERS ON MECHANICAL PROPERTIES OF POLYURETHANE COMPOSITES}

\section{Bending test results}

In bending test, a multifunctional testing machine is used to load and dynamic strain acquisition instrument is used to collect. By averaging the values of the two strain gauges, the actual strain value can be derived. There are three flexural test blocks of group A polyurethane cement participating in the flexural test this time. The flexural stress-strain curve of group A polyurethane cement test blocks is shown in Figure 8 and the average is shown in Figure 9. Strain and stress present a positive proportional function in the curve. The peak strength is $37.2 \mathrm{MPa}$. The peak strain is $10848 \mu \varepsilon$. The peak stress of each block is shown in Table 3. 


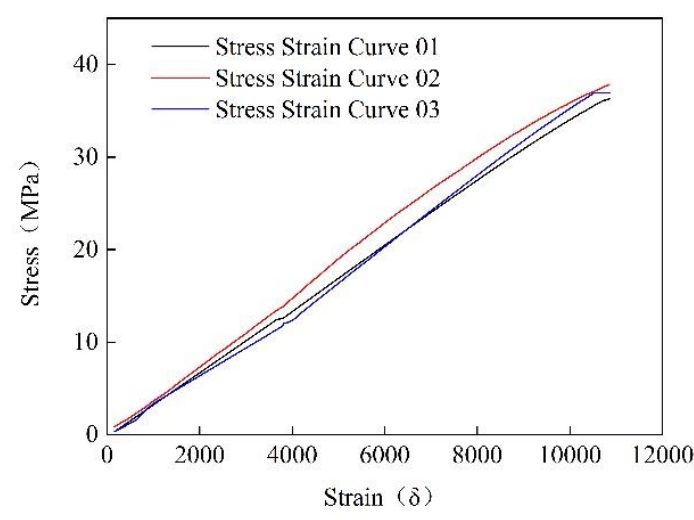

Fig. 8- Stress and strain curve of group $A$

(The material ratio is 1:1:2)

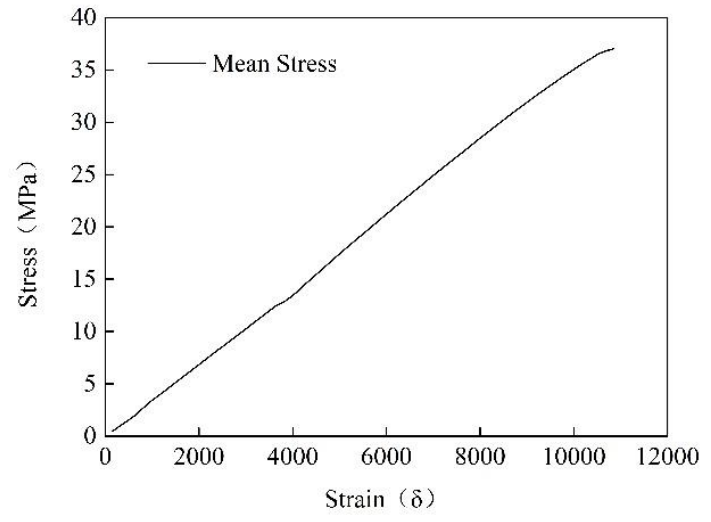

Fig. 9 - Stress and strain curve of group $A$

(The material ratio is 1:1:2)

Tab. 3 - The flexural strength of group A polyurethane cement

\begin{tabular}{|c|c|c|c|c|}
\hline Serial Number & 1 & 2 & 3 & Average \\
\hline Strength (MPa) & 36.3 & 37.8 & 37.0 & 37.2 \\
\hline
\end{tabular}

There are three flexural test blocks of group B polyurethane cement (polyol: isocyanate: cement $=1.15: 1: 2)$ participating in the flexural test this time. The flexural curve of group $B$ polyurethane cement test blocks are shown in Figure 10 and Figure 11. The curve reveals a linear relationship with the load increasing. The average peak flexural strength is $38.9 \mathrm{MPa}$. Meanwhile, the strain peak value is $23520 \mu \varepsilon$. The peak stress of each bending specimen is shown in Table 4 . The results show that the stress of polyurethane cement increased by $1.8 \mathrm{MPa}$ and strain increased by $116.7 \%$ compared with group A polyurethane cement (polyol: isocyanate: cement =1:1:2) due to the addition of polyester polyols. The flexural strength of cement $=1.15: 1: 2$ is slightly improved, and the ductility is greatly enhanced.

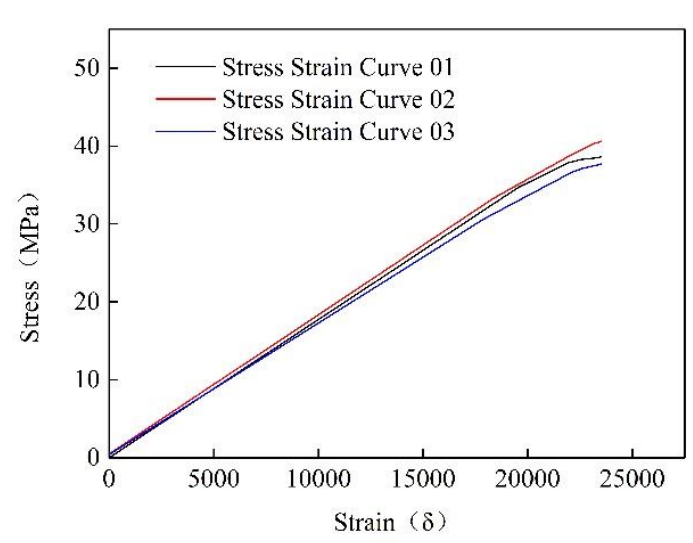

Fig. 10 - Stress-strain curve of group $A$ polyurethane cement

(Polyol: isocyanate: cement $=1.15: 1: 2$ )

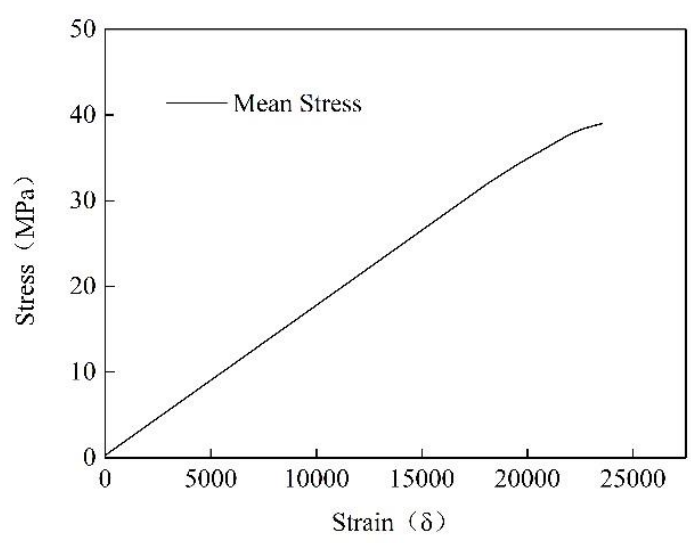

Fig. 11 - Stress-strain curve of group $A$ polyurethane cement (average)

(Polyol: isocyanate: cement $=1.15: 1: 2$ ) 
Tab. 4 - The flexural strength of group B polyurethane cement

\begin{tabular}{|c|c|c|c|c|}
\hline Serial Number & 1 & 2 & 3 & Average \\
\hline Strength (MPa) & 38.6 & 40.6 & 37.7 & 38.9 \\
\hline
\end{tabular}

The flexural curve of group $\mathrm{C}$ is shown in Figure 12. There are three flexural test blocks of group $C$ polyurethane cement (polyol: isocyanate: cement $=1.3: 1: 2$ ) participating in the flexural test this time. The average curve of flexural capacity is shown in Figure 13.TThe peak stress of each flexural specimen is shown in Table 5. The results showed that the stress of polyurethane cement increased by $5.4 \mathrm{MPa}$ and the strain increased by $203.5 \%$ compared with group A polyurethane cement (polyol: isocyanate: cement $=1: 1: 2$ ) due to the addition of polyester polyols. Compared with group $B$ polyurethane cement (polyol: isocyanate: cement $=1: 1: 2$ ), the stress of polyurethane cement increased by $5.4 \mathrm{MPa}$ and the strain increased by $203.5 \%$. (polyol: isocyanate: cement $=1.15: 1: 2$ ) increased by $3.6 \mathrm{MPa}$ and strain increased by $40.1 \%$, indicating that the flexural strength and ductility of polyurethane cement (polyol: isocyanate: cement $=1.3: 1: 2$ ) are improved to a certain extent with the increase of the content of polyurethane polyol.

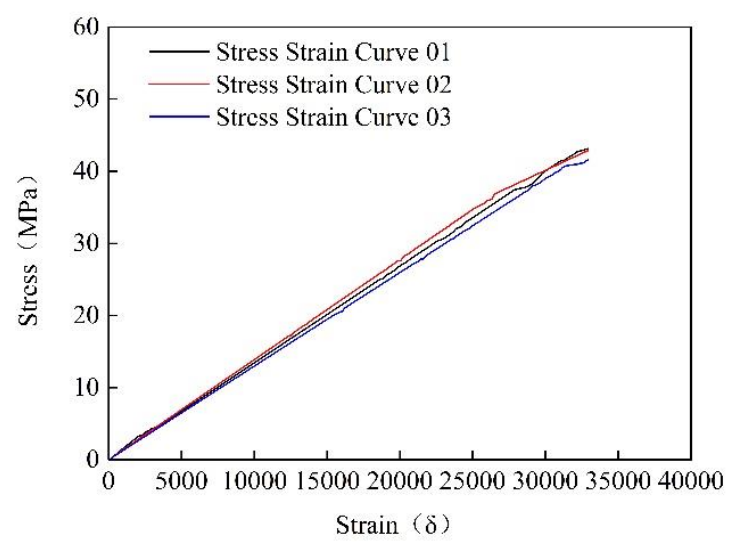

Fig.12 - Stress-strain curve of polyurethane cement

(Polyol: isocyanate: cement $=1.3: 1: 2$ )

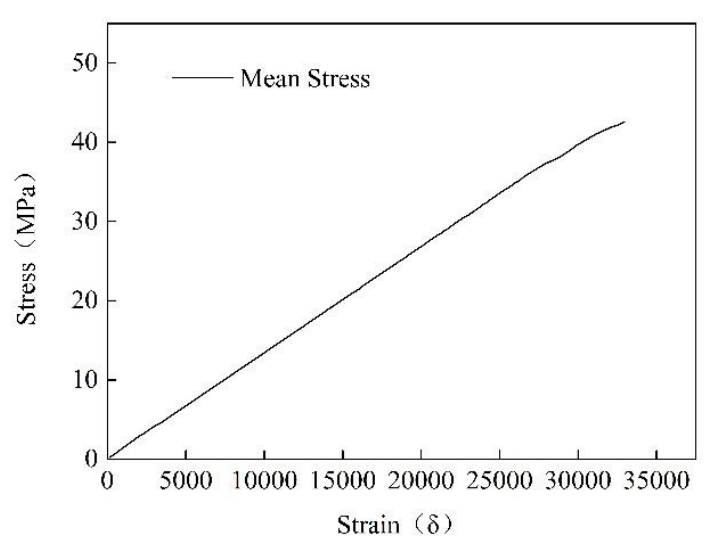

Fig. 13 - Stress-strain curve of polyurethane cement (average) (Polyol: isocyanate: cement $=1.3: 1: 2$ )

Tab.5 - The flexural strength of group B polyurethane cement

\begin{tabular}{|c|c|c|c|c|}
\hline Serial Number & 1 & 2 & 3 & Average \\
\hline Strength (MPa) & 43.1 & 42.9 & 41.6 & 42.5 \\
\hline
\end{tabular}

Three pieces of polyurethane emery flexural test blocks were used in the test. Its stress-strain curve are shown in Figure 14 and Figure 15. The average flexural strength at the peak is $45.1 \mathrm{MPa}$, and the strain is $6203 \mu \varepsilon$. The peak stress of each flexural test block is shown in Table 6. 


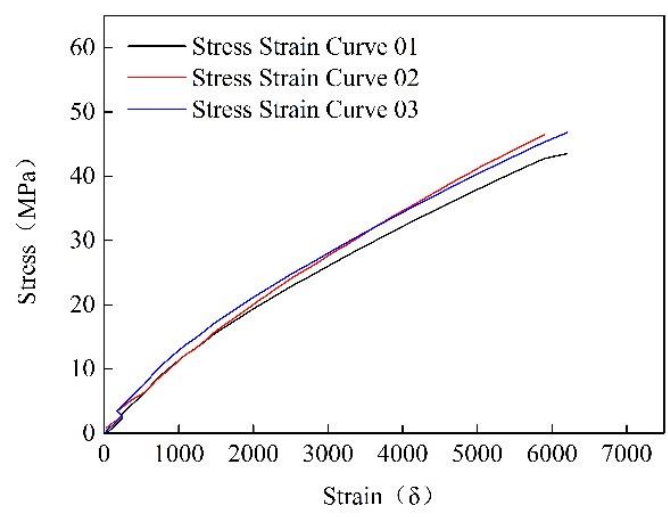

Fig.14 - Polyurethane emery curve

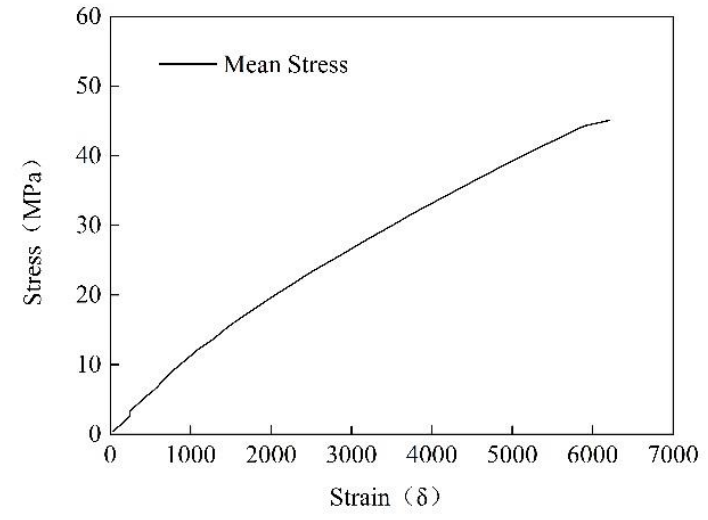

Fig. 15 - Polyurethane emery curve (average)

Tab. 6 - The flexural strength of polyurethane emery test block

\begin{tabular}{|l|c|c|c|c|}
\hline Serial Number & 1 & 2 & 3 & Average \\
\hline Strength (MPa) & 43.5 & 46.5 & 45.3 & 45.1 \\
\hline
\end{tabular}

There are three polyurethane lime flexural test blocks participating in the flexural test, which are collected by dynamic strain acquisition instrument. The flexural curve of polyurethane lime test block is shown in Figure 16 and Figure 17. The peak average flexural strength is $31.4 \mathrm{MPa}$. At the same time, the strain is $5723 \mu \varepsilon$. When the loading reached a certain peak, the stress increased more slowly than the strain. When the load reaches the peak value. The peak flexural strength of each polyurethane lime test block is shown in Table 7.

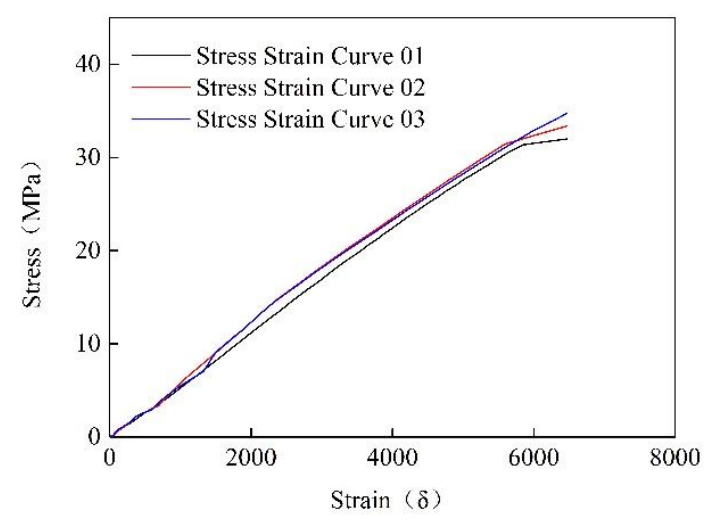

Fig. 16 - Stress and strain curve of polyurethane lime

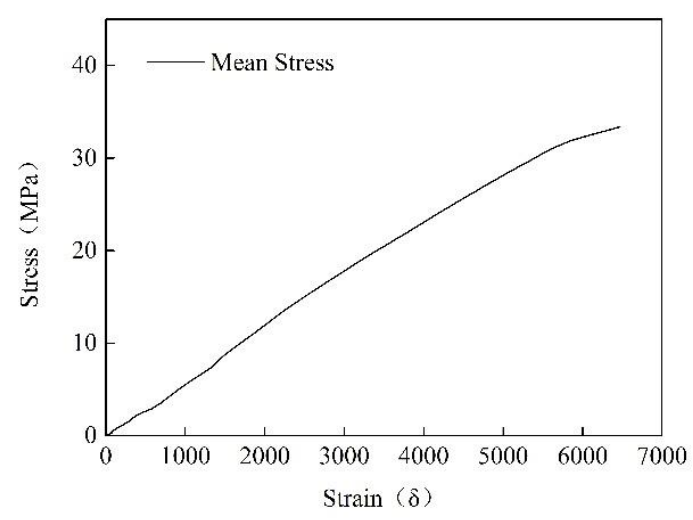

Fig. $17-$ Stress and strain curve of polyurethane lime (average)

Tab. 7 - The flexural strength of polyurethane lime test blocks

\begin{tabular}{|c|c|c|c|c|}
\hline Serial Number & 1 & 2 & 3 & Average \\
\hline Strength (MPa) & 32.0 & 33.4 & 34.7 & 33.4 \\
\hline
\end{tabular}




\section{CIVIL}

ENGINEERING JOURNAL

There are three flexural test blocks of polyurethane quartz sand participating in the flexural test this time. The curve of polyurethane quartz sand test blocks is shown in Figure 18 and Figure 19. The peak stress of each polyurethane flexural test block is shown in Table 9 . The slope of the stress-strain curve decreases slightly when the loading reaches the middle and late stage, and the stress increases more slowly than the strain. When the loading reaches the peak, the average flexural strength is $49.2 \mathrm{MPa}$, and the strain is $7521 \mu \varepsilon$. It can be seen that in the rubber sand sample composed of polyurethane, emery, lime and quartz sand, the test block of polyurethane quartz sand has the best flexural strength and higher strain than other composites, indicating that its ductility is also better than other composites.

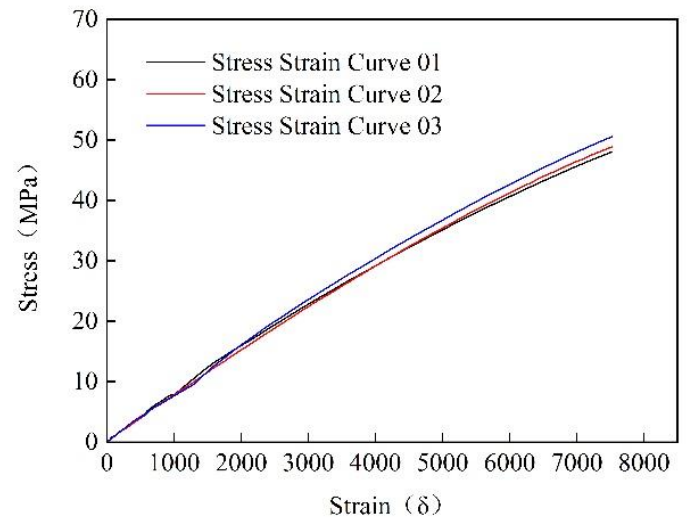

Fig. 18 - Stress and strain curve of polyurethane quartz sand

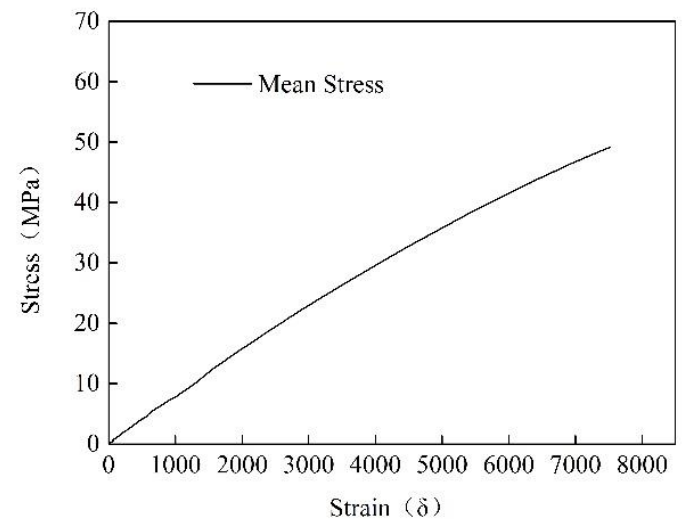

Fig. 19 - Stress and strain curve of polyurethane quartz sand (average)

Tab.9 - The flexural strength of polyurethane quartz sand test block

\begin{tabular}{|c|c|c|c|c|}
\hline Serial Number & 1 & 2 & 3 & Average \\
\hline Strength (MPa) & 48.1 & 48.9 & 50.6 & 49.2. \\
\hline
\end{tabular}

Table 10 is a summary of the average flexural strength of each polyurethane powder composite. As shown in Table 10, the flexural strength of the polyurethane cement in the polyurethane mortar test blocks with the same composition ratio is $37.1 \mathrm{MPa}$, and the average flexural strength of the polyurethane emundant test block is $45.1 \mathrm{MPa}$, which is $21.6 \%$ higher than that of the polyurethane cement test block in group $A$. The average flexural strength of polyurethane lime test block is $33.4 \mathrm{MPa}$, which is $9.9 \%$ lower than that of group A polyurethane cement test block. The average flexural strength of polyurethane quartz sand test block is $49.2 \mathrm{MPa}$, which is $32.6 \%$ higher than that of group A polyurethane cement test block. These three kinds of the strength of the polyurethane lime block only less than the flexural strength of polyurethane cement group $A$, while polyurethane emery block polyurethane and quartz sand block strain less than polyurethane cement, but its flexural strength is superior to polyurethane, the flexural strength of cement in theory can replace cement with silicon carbide, quartz powder to reduce the cost of PU composite material. 


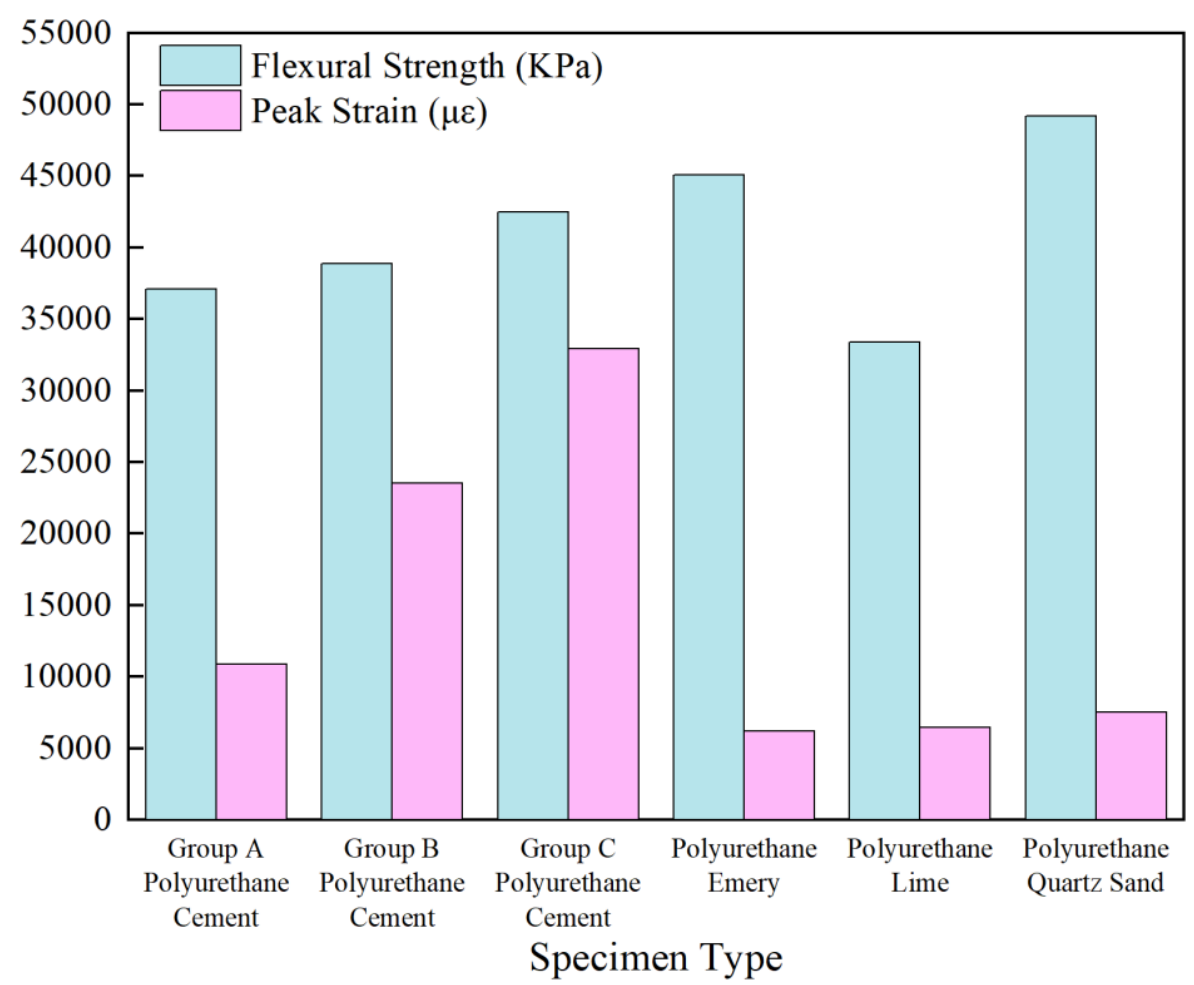

Fig. 20 - Summary of the flexural strength of each specimen

\subsection{Compression test results}

In compression test, the strain value is the average of the measured values of the two resistance strain gauges. The compressive stress-strain curve of each test block is shown in Figure 21 and Figure 22. At the initial stage of loading, the compressive strength of the six groups of cube specimens is very similar. In the later stage of loading, the stress-strain curve is nonlinear. In the three groups of polyurethane cement. The compressive strength of group $\mathrm{C}$ is the highest with a value of $71.52 \mathrm{MPa}$. In the three groups of other materials. In the other three groups of polyurethane powder types, polyurethane quartz sand has the greatest compressive strength. Its maximum compressive strength is $76.70 \mathrm{MPa}$.

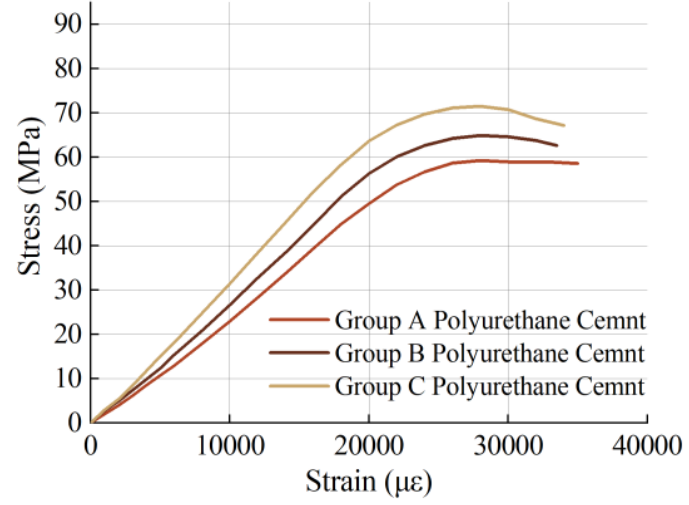

Fig. 21 - Compression strength of polyurethane cement

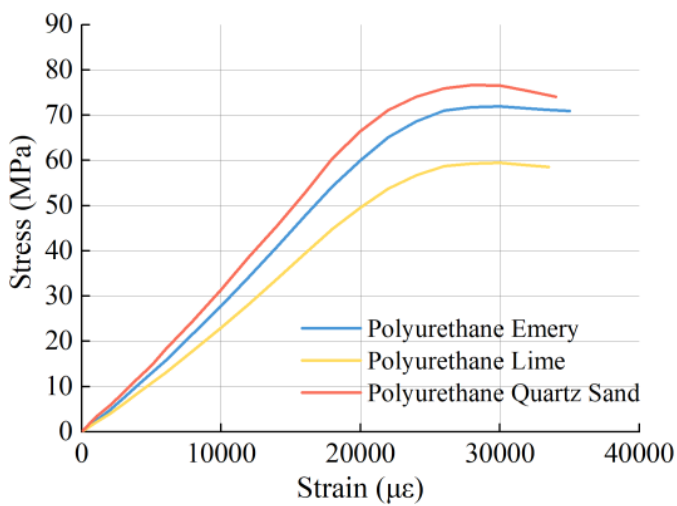

Fig. 22 - Compression strength of other polyurethane powder 


\section{CONCLUSION}

In this paper, by studying the influence of different powders on the mechanical properties of polyurethane powder composites, the powder is mainly divided into emery, lime, quartz sand and cement. The stress-strain curve and the following conclusions can be listed as follows:

1. The average peak flexural strength of group A polyurethane cement (polyol: isocyanate: cement $=1: 1: 2$ ) is $37.1 \mathrm{MPa}$, and the strain is $10854 \mu \varepsilon$. The average peak flexural strength of polyurethane cement of group $B$ (polyol: isocyanate: cement $=1.15: 1: 2$ ) is $38.9 \mathrm{MPa}$, and the strain is $23520 \mu \varepsilon$. Compared with group $A$, the stress of polyurethane cement of group B is $1.8 \mathrm{MPa}$ higher and the strain is $116.7 \%$. The average peak flexural strength of group $\mathrm{C}$ polyurethane cement (polyol: isocyanate: cement $=1.3: 1: 2$ ) is $42.5 \mathrm{MPa}$, and the strain is $32942 \mu \varepsilon$. Compared with group A polyurethane cement, the stress increases by $5.4 \mathrm{MPa}$ and the strain increases by $203.5 \%$. The results show that the flexural strength and ductility of polyurethane cement are improved obviously because the composition proportion of polyester polyols is increased in polyurethane cement. In the compressive test, the maximum compressive strength is $76.70 \mathrm{MPa}$. The material composition with maximum compressive strength is polyurethane quartz sand.

2. The average peak flexural strength of polyurethane emery test block is $45.1 \mathrm{MPa}$, and the strain is $6203 \mu \varepsilon$. The average peak flexural strength of polyurethane lime test block is $33.4 \mathrm{MPa}$, and the strain is $6470 \mu \varepsilon$. The average peak flexural strength of polyurethane quartz sand test block is $49.2 \mathrm{MPa}$, and the strain is $7521 \mu \varepsilon$. In the flexural test blocks composed of polyurethane and emery, lime and quartz sand, the flexural strength of polyurethane lime test block is less than that of polyurethane cement, and the flexural strength of polyurethane emery test block and polyurethane quartz sand test block is greater than that of polyurethane cement. As a summary, emery and quartz sand powder can be used to replace cement in order to reduce the cost of polyurethane composites.

\section{ACKNOWLEDGEMENTS}

Thanks to the Open Fund Project of Laboratoryof Ministry of Education for Disaster and Control of Major Engineering, Jinan University (20200904012)

\section{REFERENCES}

[1] XUE, Rui, WU, Yu, ZHOU, \& Junmin. Research And Application Of Bridge Reinforcement.

[2] D Bennett. ,2008. The history and aesthetic development of bridges. Thomas Telford.

[3] Podolny, W. , \& Fleming, J. F. ., 1972. History development of cable-stayed bridges. Journal of the Structural Division, 98.

[4] Fang, R. , \& Yang, X. ., 2015. Cause and Countermeasure of Structure Disease of Bridge.

International Conference on Transportation Information \& Safety.

[5] Diao, \& Yan. (2014). Stone arch bridge disease detection and evaluation. Applied Mechanics \& Materials, 501-504, 1332-1335.

[6] Fu, Z. , Sun, G. , Tong, S. , \& Jie, X. ., 2017. Research on fatigue diseases evaluation of steel bridge deck based on fuzzy comprehensive method. Industrial Construction.

[7] Kang, J. T. , Wang, N. , Liu, C. Z. , Chen, C. W. , \& Li, L. ., 2011. Study on disease analysis and reinforcement technology of truss arch bridge. Advanced Materials Research, 243-249, 1972-1977.

[8] Li, H. , \& F Liu. , 2015. Bridge Inspection and Reinforcement Technology Application.

[9] Zhu, H. , Yang, Y. , \& Fan, W. , 2015. External prestressing bridge reinforcement technology review. Matec Web of Conferences.

[10] Chen, K. , Wang, C. , Wang, T., Zhu, Z. , \& Jiang, H. , 2020. Preparation and performances of form-stable polyethylene glycol/methylcellulose composite phase change materials. Journal of Polymer Research, 27(8).

[11] Sonoda, K. , Okino, M. , Hayashi, H. , \& Kita, H. ., 2010. Reliability of epoxy bonded steel plate method for repairing damaged rc slabs of bridge. Proceedings of the Japan Society of Civil Engineers(398), 245-254. 


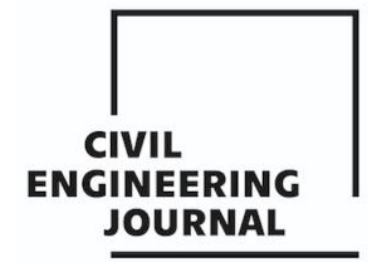

Article no. 67

THE CIVIL ENGINEERING JOURNAL 4-2021

[12] Zhao, S. W. , \& Qiao, X. P. ., 2011. Experimental study on reinforced hollow beam with carbon fiber reinforced polymer and external prestressed strand. Applied Mechanics \& Materials, 94-96, 495-499.

[13] Gang, Zhishen, Wei, Yang, Jiang, \& Jianbiao, et al. , 2014. Flexural strengthening of $r c$ beams using distributed prestressed high strength steel wire rope: theoretical analysis. Structure \& Infrastructure Engineering: Maintenance, Management, Life-Cycl.

[14] Gang, Zhishen, Wei, Yang, Jiang, \& Jianbiao, et al. , 2014. Flexural strengthening of rc beams using distributed prestressed high strength steel wire rope: theoretical analysis. Structure \& Infrastructure Engineering: Maintenance, Management, Life-Cycl.

[15] Zhang, K. , \& Sun, Q. ., 2018. Experimental study of reinforced concrete t-beams strengthened with a composite of prestressed steel wire ropes embedded in polyurethane cement (pswr-puc). International Journal of Civil Engineering,Transaction A:Civil Engineering, 16(9), 1109-1123.

[16] Zhang, J. F. , Zhuang, B. Z. , \& Zhang, K. X. ., 2016. Experimental study to investigate mechanical properties of polyurethane-cement composite. Low Temperature Architecture Technology.

[17] Zhang, H. X. , Chen, C. , \& Tian-Lai, Y. U. ., 2015. The application of simply supported t beam strengthened by mpc material. Low Temperature Architecture Technology.

[18] Hussain, H. K. , Lian, Z. Z. , \& Gui, W. L. . , 2013. An experimental study on strengthening reinforced concrete t-beams using new material poly-urethane-cement (puc). Construction \& Building Materials, 40(Mar.), 104-117.

[19] Dan-Dan, G. U. , Sun, Q. S. , \& University, N. F. ., 2015. Study of static tests for using mpc composite material to strengthen void plate girder bridge. World Bridges.

[20] Lee, Y. H. , Oh, S. H. , Lee, J. K. , \& Chung, Y. S. ., 2011. A structural performance test of reinforced concrete bridge slab with inverted-t girder. Journal of the Korean Society of Civil Engineers B. 31 2 a, $31(2 A)$.

[21] Hussain, H. K. , Lian, Z. Z. , \& Gui, W. L. ., 2013. An experimental study on strengthening reinforced concrete t-beams using new material poly-urethane-cement (puc). Construction \& Building Materials, 40(Mar.), 104-117.

[22] Hussain, H. K. , Liu, G. W. , \& Yong, Y. W. ., 2014. Experimental study to investigate mechanical properties of new material polyurethane-cement composite (puc). Construction \& Building Materials, 50 (jan.), 200-208.

[23] Liu, G. , Otsuka, H. , Mizuta, Y. , \& Shimitsu, A. ., 2006. A foundational study on static mechanical characteristics of the super lightweight and high strength material using fly-ash. Journal of the Society of Materials Science Japan, 55(8), 738-745. 